\title{
Sintesis dan Karakterisasi Kalsium Oksida dari Limbah Cangkang Bekicot (Achatina fulica)
}

\author{
Edi Kurniawan ${ }^{1 *}$, Asregi Asril ${ }^{1}$, Jumriana Rahayu Ningsih ${ }^{1}$ \\ 1,2,3 Program Studi Pend. Kimia, Universitas Islam Kuantan Singingi Kuantan, Kuantan Singingi, Riau, 29566
}

\begin{abstract}
ABSTRAK
Limbah cangkang bekicot (Achatina fulica) memiliki potensi untuk dikembangkan sebagai sumber Kalsium Oksida (CaO). Limbah cangkang bekicot (Achatina fulica) memiliki kandungan mineral kalsium karbonat $\left(\mathrm{CaCO}_{3}\right)$ yang tinggi. $\mathrm{CaCO}_{3}$ dapat didekomposisi menjadi $\mathrm{CaO}$ pada pemanasan suhu tinggi. Dalam penelitian ini, $\mathrm{CaO}$ disintesis dari Limbah cangkang bekicot (Achatina fulica) dikalsinasi $900^{\circ} \mathrm{C}$ selama 10 jam (LCB-900-10) dan kemudian CaO yang dihasilkan dari proses kalsinasi dikarakterisasi menggunakan $X$-Ray Diffraction (XRD) dan $X$ Ray Fluorocense (XRF). Dari hasil difraktogram XRD senyawa CaO dari LCB-900-10 terdapat puncak lime yang berturut-turut beserta nilai intensitas relatif yang cukup besar di antaranya adalah pada $2 \theta=32,1767^{\circ}(37,9 \%) ; 37,3224^{\circ}(100 \%) ; 53,8253^{\circ}(55,42 \%) ; 64,1206^{\circ}(15,76 \%)$; $67,3433^{\circ} \quad(16,32 \%) ; 79,6249^{\circ} \quad(5,08 \%) ; 84,7873^{\circ} \quad(0,22 \%) ; 88,4925^{\circ} \quad(5,35 \%) ; 91,4306^{\circ}$ $(14,88 \%)$, dengan kandungan $\mathrm{CaO}$ dilihat dari karakterisasi menggunakan XRF sebesar $98,629 \%$.
\end{abstract}

Kata Kunci : Limbah cangkang bekicot ; Kalsium Oksida; Difraksi Sinar X

\begin{abstract}
Waste of snail shells (Achatina fulica) have the potential to be developed as a natural source of $\mathrm{CaO}$. Waste of snail shells (Achatina fulica) has a high calcium carbonate $\left(\mathrm{CaCO}_{3}\right)$ mineral content. $\mathrm{CaCO}_{3}$ can be decomposed into $\mathrm{CaO}$ at high temperature heating. In this study, $\mathrm{CaO}$ catalysts were synthesized from Snail shells (Achatina fulica) waste calcined $900{ }^{\circ} \mathrm{C}$ for 10 hours (LCB-900-10) and then $\mathrm{CaO}$ produced from the calcination process was characterized using X-Ray Diffraction (XRD) and X-Ray Fluorocense (XRF). From the XRD diffractogram of CaO compounds from LCB-900-10, there are consecutive lime peaks along with a relatively large relative intensity of which is at $2 \theta=32.1767^{\circ}(37.9 \%) ; 37,3224^{\circ}(100 \%) ; 53,8253^{\circ}$

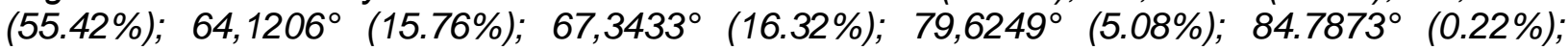
$88.4925^{\circ}(5.35 \%) ; 91.4306^{\circ}(14.88 \%)$, with $98.629 \% \mathrm{CaO}$ content seen from XRF characterization.
\end{abstract}

Keywords : Achatina fulica Waste; Calcium Oxide; X-Ray Diffraction

Received: 19-07-2019, Accepted: 11-09-2019, Online: 30-09-2019

\section{PENDAHULUAN}

Limbah merupakan produk samping dari aktivitas makhluk hidup. Limbah sering menimbulkan permasalahan lingkungan hidup yang serius dan akhir-akhir ini menjadi pusat perhatian oleh pemerintah karena dampak negatif yang ditimbulkannya (Lubis,

${ }^{\star}$ Corresponding author:

edi.kurniawan@grad.unri.ac.id 
2007). Terlepas dari banyak nya efek negatif yang ditimbulkannya, limbah juga memiliki banyak manfaat apabila diolah dengan cara yang baik dan benar (Indahyani, 2011).

Salah satu limbah yang sering kita lihat adalah limbah cangkang bekicot (Achatina fulica). Negara tropis seperti Indonesia menjadi tempat yang baik bagi hewan moluska salah satunya adalah bekicot (Achatina fulica) untuk berkembang biak. Perkembangan biakan yang pesat sering diiringi dengan banyak nya cangkang bekicot (Achatina fulica) yang berserakan dan tidak diberdaya gunakan sehingga menjadi limbah. Penelitian ini bertujuan untuk mengolah limbah cangkang bekicot (Achatina fulica) menjadi senyawa Kalsium Oksida $(\mathrm{CaO})$ alamiah dengan cara kalsinasi cangkang bekicot (Achatina fulica) pada suhu tinggi dan waktu tertentu. Karakterisasi yang dilakukan bertujuan untuk mengetahui kandungan $\mathrm{CaO}$ yang dihasilkan. Diharapkan penelitian ini dapat menghasilkan $\mathrm{CaO}$ yang dihasilkan dari limbah cangkang bekicot (Achatina fulica) lebih murah dan ekonomis daripada $\mathrm{CaO}$ yang dijual di toko-toko bahan kimia.

Dalam penelitian terakhir, banyak limbah yang dapat digunakan sebagai sumber $\mathrm{CaO}$ alami, seperti limbah cangkang kerang (Anadara granosa), cangkang hewan moluska, cangkang telor, dan tulang. Cangkang kerang darah (Anadara granosa) memiliki kandungan mineral kalsium karbonat $\left(\mathrm{CaCO}_{3}\right)$ yang tinggi dan mengandung $\mathrm{CaO}$ alami sebesar 99,09\% (b/b) (Nurhayati dkk., 2016), cangkang kerang mutiara (Pinctada maxima) mengandung $\mathrm{CaO}$ alami sebesar 52,23\% (Rahayu dkk, 2018), cangkang telor dan bebek mengandung bubuk 65,67\% dan 55,02\% (b/b) (Nurlaela dkk, 2014). Birla dkk. (2011) mengatakan bahwa komposisi unsur cangkang kerang yang dikalsinasi pada $900^{\circ} \mathrm{C}$ selama 3,5 jam mengandung unsur $\mathrm{Ca}$ sebesar $98,35 \%$. Menurut Riza dan Ediati (2013) hasil analisis XRF menunjukkan bahwa senyawa yang didapatkan dari hasil kalsinasi cangkang telur ayam pada suhu $1000^{\circ} \mathrm{C}$ tersebut mengandung 99,48\% unsur $\mathrm{Ca}$. $\mathrm{CaO}$ alami yang diperoleh dari limbah cangkang menunjukkan potensi yang baik karena selain ramah lingkungan, $\mathrm{CaO}$ alami yang diperoleh juga berbiaya rendah.

Pada penelitian ini, limbah cangkang bekicot (Achatina fulica) digunakan sebagai sumber $\mathrm{CaO}$ alami. Limbah cangkang bekicot (Achatina fulica) memiliki karakteristik yang mirip baik secara fisik maupun kimia dengan limbah cangkang kerang. Limbah cangkang bekicot (Achatina fulica) terdekomposisi termal melalui kalsinasi pada suhu tinggi. $\mathrm{CaCO}_{3}$ yang terkandung pada limbah cangkang bekicot (Achatina fulica) akan terdekomposisi menjadi $\mathrm{CaO}$ pada suhu diatas $700{ }^{\circ} \mathrm{C}$ (Viriya dkk, 2010; Boey dkk, 2009).

\section{METODE PENELITIAN}

\section{Alat dan Bahan}

Peralatan yang digunakan dalam penelitian ini dibedakan menjadi alat ukur dan alat preparasi, alat ukur antara lain X-Ray Diffraction (Philip Analytical X-Ray B.V.), XRay Fluorescence (Horiba XGT-1000WR), sedangkan alat preparasi antara lain mortar, oven (GallenKemp), furnace (Vulcan ${ }^{T M}$ seri $A-300$ ), ayakan 200 mesh, neraca analitik (mettler $A E$ 200), desikator, dan peralatan gelas penelitian lainnya sesuai dengan prosedur kerja.

Bahan-bahan yang digunakan dalam penelitian ini adalah cangkang Bekicot (Achatina fulica), Aquades, dan bahan-bahan kimia lainnya yang sesuai dengan prosedur kerja. 


\section{Prosedur Kerja}

Limbah cangkang bekicot (Achatina fulica) dibersihkan dari sisa-sisa kotoran yang menempel kemudian direbus selama 0,5 jam. Setelah itu cangkang dikeringkan dan kembali dibersihkan dengan menggunakan aquades. Limbah cangkang bekicot (Achatina fulica) kemudian dipanaskan dengan oven pada suhu $105^{\circ} \mathrm{C}$ selama 2 jam. Setelah itu, limbah cangkang bekicot (Achatina fulica) digerus menggunakan mortar dan disaring menggunakan ayakan 200 mesh kemudian dikalsinasi pada suhu $900{ }^{\circ} \mathrm{C}$ selama 10 jam. Limbah cangkang bekicot (Achatina fulica) hasil kalsinasi (LCB-900-10) digerus kembali menggunakan mortar dan dipanaskan kembali menggunakan oven pada suhu $120^{\circ} \mathrm{C}$ selama 3 jam, kemudian disimpan didalam desikator (Nurhayati dkk, 2013). Senyawa LCB-900-10 hasil kalsinasi kemudian dikarakterisasi menggunakan $X$ Ray Diffraction (XRD), dan X-Ray Fluoroscence (XRF).

\section{HASIL DAN PEMBAHASAN}

Jenis mineral dari LCB-900-10 disajikan pada gambar 1. Intensitas yang ditunjukkan pada $2 \theta=32,1767^{\circ}(37,9 \%) ; 37,3224^{\circ}(100 \%) ; 53,8253^{\circ}(55,42 \%)$; $64,1206^{\circ}(15,76 \%) ; 67,3433^{\circ}(16,32 \%) ; 79,6249^{\circ}$ (5,08\%); 84,7873 $(0,22 \%) ; 88,4925^{\circ}$ $(5,35 \%)$; dan $91,4306^{\circ}(14,88 \%)$ menunjukkan puncak $\mathrm{CaO}$ (JCPDS 881811), puncak $\mathrm{Ca}(\mathrm{OH})_{2}$ pada $2 \Theta=18,0193^{\circ}(3,21) ; 28,6611^{\circ}(2,00) ; 34,0589^{\circ}(7,48) ; 47,0691^{\circ}(1,96)$; $50,7749^{\circ}(2,22) ; 71,8528^{\circ}(0,23) ; 93,2193^{\circ}(0,29)$ (JCPDS 841266), dan puncak $\mathrm{CaCO}_{3}$ pada $2 \theta=29,3690^{\circ}(0,87) ; 48,3626^{\circ}(0,28) ; 62,6144^{\circ}(0,53)($ JCPDS 050586).

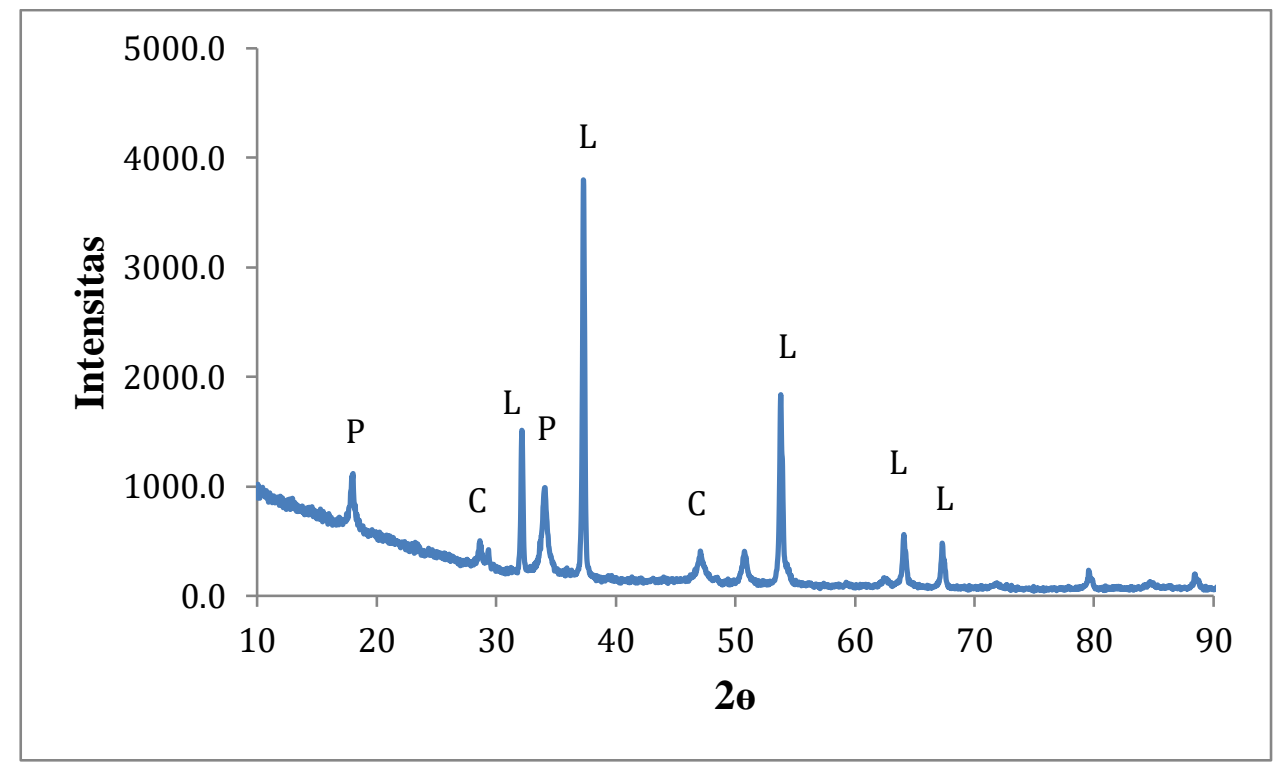

Gambar 1. Difraktogram XRD Senyawa LCB-900-10

Berdasarkan gambar 1 juga dapat dilihat bahwa banyak kandungan mineral lime $(\mathrm{CaO})$ yang terbentuk dengan intensitas yang tinggi. Hal ini disebabkan oleh banyaknya mineral calcite $\left(\mathrm{CaCO}_{3}\right)$ yang terdekomposisi menjadi mineral lime $(\mathrm{CaO})$. Menurut Alonso dkk. (2009) menyatakan bahwa optimumnya proses dekomposisi mineral calcite $\left(\mathrm{CaCO}_{3}\right)$ dan dehidrasi portlandite $\mathrm{Ca}(\mathrm{OH})_{2}$ menjadi lime $\mathrm{CaO}$ terjadi pada suhu diatas $773 \mathrm{~K}$.

Masih munculnya mineral portlandite, $\mathrm{Ca}(\mathrm{OH})_{2}$ pada penelitian ini disebabkan oleh adanya kontak antara permukaan padatan $\mathrm{CaO}$ dengan uap air dari udara bebas (Kouzu dkk., 2008). Sedangkan kemungkinan lain yang menyebabkan masih munculnya mineral calcite $\mathrm{CaCO}_{3}$ pada penelitian ini adalah cangkang kerang mempunyai lapisan yang sangat keras sehingga kalsinasi pada suhu dan waktu 
tersebut masih belum menghasilkan perubahan sempurna $\mathrm{CaCO}_{3}$ menjadi $\mathrm{CaO}$ (Nurhayati dkk., 2013)

Tabel 1.Analisis Komposisi Senyawa LCB-900-10 Menggunakan XRF

\begin{tabular}{ccc}
\hline \multirow{2}{*}{ No } & Komposisi & Kadar (\%) \\
\cline { 3 - 3 } & & LCB-900-10 \\
\hline 1 & $\mathrm{Al}_{2} \mathrm{O}_{3}$ & 0,699 \\
2 & $\mathrm{SiO}_{2}$ & 0,572 \\
3 & $\mathrm{SO}_{3}$ & 0,095 \\
4 & $\mathrm{CaO}$ & 98,629 \\
5 & $\mathrm{TiO}_{2}$ & 0,005 \\
& Total & 100 \\
\hline
\end{tabular}

Hasil sintesis pada tabel 1 menunjukkan senyawa dengan konsentrasi tertinggi pada senyawa LCB-900-10 yakni $\mathrm{CaO}(98,63 \%), \mathrm{Al}_{2} \mathrm{O}_{3}(0,699 \%), \mathrm{SiO}_{2}(0,572 \%), \mathrm{SO}_{3}$ $(0,095 \%), \mathrm{TiO}_{2}(0,005 \%)$. Birla dkk. (2011) mengatakan bahwa komposisi unsur cangkang kerang yang dikalsinasi pada $900^{\circ} \mathrm{C}$ selama 3,5 jam mengandung unsur $\mathrm{Ca}$ sebesar 98,35\%. Menurut Riza dan Ediati (2013) hasil analisis XRF menunjukkan bahwa senyawa yang didapatkan dari hasil kalsinasi cangkang telur ayam pada suhu $1000^{\circ} \mathrm{C}$ tersebut mengandung $99,48 \%$ unsur $\mathrm{Ca}$. Kandungan $\mathrm{Ca}$ yang tinggi, pada limbah cangkang bekicot (Achatina fulica) sangat berpotensi untuk menjadi sumber $\mathrm{CaO}$ yang ekonomis. Keberadaan senyawa oksida selain $\mathrm{CaO}$ kemungkinan disebabkan oleh adanya senyawa lain yang yang ikut bereaksi ketika proses sintesis dilakukan.

\section{SIMPULAN}

Limbah cangkang bekicot (Achatina fulica) berpotensi digunakan sebagai sumber alternatif CaO.Dimana hasil difraktogram XRD senyawa $\mathrm{CaO}$ dari LCB-90010terdapat puncak lime yang berturut-turut beserta nilai intensitas relatif yang cukup besar, dengan kandungan $\mathrm{CaO}$ dilihat dari karakterisasi menggunakan XRF sebesar $98,629 \%$.

\section{UCAPAN TERIMA KASIH}

Penulis mengucapkan terima kasih kepada Lembaga Penelitian dan Pengabdian Kepada Masyarakat (LPPM) Universitas Islam Kuantan Singingi yang telah membiayai dan membantu sehingga penelitian ini dapat diselesaikan.

\section{DAFTAR RUJUKAN}

Lubis, Abubakar. 2007. Energi Terbarukan dalam Pembangunan Berkelanjutan. Jurnal Teknologi Lingkungan. 8(2) : 155-162.

Alonso, D. M., Granados, M. L., Mariscal R., and Douhail, A. 2009. Surface Chemical Promotion of $\mathrm{Ca}$ Oxide Catalyst in Biodiesel Production Reaction by the Addition of Monoglycerides, Diglycerides, and Glycerol. Journal Catalyst. 276: 229-236. 
Birla, A., Singh, B., Upadhyay, S.N, and Sharma, Y.C. 2012. Kinetics Studies of Synthesis of Biodiesel from Waste Frying Oil Using a Heterogeneous Catalyst Derived from Snail Shell. Bioresource Technology. 106: 95-100.

Boey, P.-L., Maniam, G.P., Hamid, S.A., 2009, Biodiesel Production Via Transesterification of Palm Olein Using Waste Mud Crab (Scylla Serrata) Shell as a Heterogeneous Catalyst, Bioresource Technology 100, 6362-6368.

Kouzu, M., Kasuno, T., Tajika M., Zugimoto, Y., Yamanaka, S., Hidaka J. 2008.Calcium oxide as a solid base catalyst for transesterification of soybean oil and its application to biodiesel production. Fuel, 87(12): $2798-2806$.

Nurhayati, Muhdarina, Linggawati A., Anita S., and Amri A. T. 2016. Preparation and Characterization of Calcium Oxide Heterogeneous Catalyst Derived from Anadara Granosa Shell for Biodiesel Synthesis. J.KnE Engineering, 2015 : 1-8.

Nurhayati, Muhdarina, Amri, T. A., dan Susanto., 2013. Sintesis Biodiesel dengan Katalis Lempung Palas Aktivasi $\mathrm{NaOH}$ yang Dikalsinasi pada Suhu 300 ${ }^{\circ}$ C.Prosiding Semirata FMIPA Universitas Lampung. FMIPA Universitas Riau, Pekanbaru.

Nurlaela, DewizSU., Dahlan K., Soejoko, DS. 2014. Pemanfaatan Limbah Cangkang Telur dan Bebek sebagai Sumber Kalsium untuk Sintesis Mineral Tulang.Jurnal Pendidikan Fisika Indonesia10 : 81-85.

Rahayu, Kurniawidi, WD., Gani A. 2018. Pemanfaatan Limbah Cangkang Kerang Mutiara (Pinctada maxima) sebagai Sumber Hidroksiapatit.Jurnal Pendidikan Fisika dan Teknologi, 4 (2): 226-231.

Riza, E., and Ediati, R. 2013. Pemanfaatan Kulit Telur Ayam dan Abu Layang Batubara sebagai Katalis Heterogen untuk Reaksi Transesterifikasi Minyak Nyamplung (Calophyllum Inophyllum Linn), Fuel. 7 (1): 2337-3520.

Indahyani, Titi .2011. Pemanfaatan Limbah Sabut Kelapa pada Perencanaan Interior dan Furniture yang Berdampak pada Pemberdayaan Masyarakat Miskin. Humaniora. 2 (1): 15-23.

Viriya, N., Krasae, P., 2009. Waste shells of Mollusk and Egg as Biodiesel Production Catalysts. Bioresource Technology 101, 3765 - 3767. 